\title{
FLORESCIMENTO DE GRAMÍNEAS FORRAGEIRAS CULTIVADAS SOB LUMINOSIDADE REDUZIDA
}

\author{
FLOWERING OF FORAGE GRASSES CULTIVATED UNDER REDUCED LIGHT
}

\author{
Carlos Renato Tavares de Castro ${ }^{1}$ Margarida Mesquita Carvalho $^{2}$
}

RESUMO

Foram feitas observações relativas ao florescimento de seis espécies de gramíneas forrageiras tropicais cultivadas sob condições de luminosidade reduzida. Os resultados indicam efeito negativo do sombreamento sobre a floração da maioria das espécies estudadas, sendo recomendados novos ensaios visando à quantificação das sementes produzidas e à avaliação da qualidade fisiológica dessas.

Palavras-chave: gramíneas, sombreamento, florescimento.

\section{SUMMARY}

The influence of reduced light on the flowering of six tropical grass forage was studied. The results showed that shading has affected negativelly the flowering of most species and new researchs are recommended to quantify the seed production and evaluate the physiological seed quality.

Key words: grasses, shading, flowering.

O sucesso de um sistema silvipastoril depende, dentre outros fatores, da persistência do componente forrageiro do seu sub-bosque, e a autoperpetuação, nas pastagens, da maioria das gramíneas depende, essencialmente, da quantidade de sementes viáveis produzidas, variável diretamente relacionada com a intensidade de florescimento. Dessa forma, é desejável a obtenção de informações referentes ao comportamento reprodutivo de gramíneas forrageiras cultivadas sob luminosidade reduzida.

Segundo RYLE (1961), o florescimento de gramíneas forrageiras parece ser influenciado pela intensidade luminosa, mesmo quando as outras condições de cultivo são sabidamente favoráveis à floração. Observações realizadas por KNAKE (1972) demonstraram que o sombreamento promoveu redução na quantidade de inflorescências formadas em Setaria faberii, embora não tenha afetado a época de início do seu florescimento.

Apesar do decréscimo da intensidade luminosa ter promovido atraso na emissão de inflorescências em Oryzopsis miliacea (KIGEL \& KOLLER, 1970), apenas o sombreamento intenso, da ordem de $60 \%$, reduziu o percentual de colmos floridos. Da mesma forma, STRUIK (1983) observou que a redução da luminosidade na cultura do milho não apenas retardou, mas também reduziu o florescimento por induzir à parcial ou completa esterilidade das flores. RYLE (1961) relata que o sombreamento progressivo, além de atrasar a época de emissão de inflorescências em Phleum pratense, resultou em queda acentuada do percentual de perfilhos férteis. O atraso na emissão das estruturas florais, devido à baixa luminosidade ambiente, também foi constatado em Lolium perenne e Festuca pratensis, entretanto, enquanto em $L$. perenne a proporção de perfilhos férteis diminuiu com o sombreamento, na outra espécie essa proporção aumentou (RYLE, 1967).

De acordo com KAMEL (1959), a baixa intensidade luminosa prolonga o estádio vegetativo das plantas, resultando em atraso na floração de diversas espécies. Tal atraso foi observado em outras

\footnotetext{
${ }^{1}$ Engenheiro Agrônomo, Doutor, Pesquisador Visitante, bolsista recém-doutor (CNPq), Embrapa Gado de Leite, Rodovia MG 133, km 42, 36155-000, Coronel Pacheco, MG. Autor para correspondência.

${ }^{2}$ Engenheiro, Agrônomo, PhD., pesquisador da Embrapa Gado de Leite. 
gramíneas, além das já citadas, como em Setaria lutescens e $\boldsymbol{S}$. viridis (BUBAR \& MORRISON, 1984) e também em plantas ornamentais (ARMITAGE \& WETZSTEIN, 1984; KESSLER \& ARMITAGE, 1992) e frutíferas (SNELGAR $\boldsymbol{e}$ t al., 1991).

Conforme constatações de WONG \& WILSON (1980) e OLIVEIRA \& HUMPHREYS (1986), a época e a intensidade de florescimento de Panicum maximum não foram significativamente afetadas pelo sombreamento, comportamento divergente daquele, posteriormente, observado por DONG \& KROON (1994) em Cynodon dactylon, espécie em que apenas as plantas não sombreadas floresceram.

Foi conduzido um ensaio na Estação Experimental da Embrapa Gado de Leite, em Coronel Pacheco, MG, com o objetivo de estudar o florescimento de seis espécies de gramíneas forrageiras tropicais (Brachiaria brizantha cv. Marandú; Brachiaria decumbens; Melinis minutiflora; Andropogon gayanus cv. Planaltina; Panicum maximum cv. Vencedor; Setaria sphacelata cv. Kazungula) submetidas a três regimes de luminosidade (0, 30 e $60 \%$ de sombra), seguindo o delineamento em blocos ao acaso, com parcelas subdivididas e quatro repetições. Foram adotadas parcelas retangulares (níveis de sombreamento) de $6 \times 3 \mathrm{~m}$ e subparcelas (gramíneas) de $3 \times 2 \mathrm{~m}$, coletando-se dados apenas na área interna útil $(2 \times 1 \mathrm{~m})$ de cada subparcela. $\mathrm{O}$ sombreamento artificial foi obtido pela cobertura das parcelas com telas plásticas (sombrite), tendo sido imposto somente após o completo estabelecimento das forrageiras, quando se fez um corte geral de uniformização, em novembro de 1994.

As subparcelas foram cortadas a cada oito semanas a partir da colocação das telas, totalizando três cortes. Imediatamente antes do último corte, em doze de maio de 1995, estimou-se a densidade média de inflorescências por meio de um círculo de 0,58 $\mathrm{cm}$ de diâmetro $\left(0,26 \mathrm{~m}^{2}\right)$ que foi lançado três vezes, ao acaso, na área útil de cada subparcela.

Os dados referentes à densidade de inflorescências foram transformados $(x+1)$ e submetidos à análise de variância. $\mathrm{O}$ efeito do sombreamento foi analisado por meio da técnica de polinômios ortogonais e os valores médios comparados pelo teste Tukey a 5\% de significância.

O sombreamento exerceu efeito significativo sobre a densidade de inflorescências das espécies estudadas e o desdobramento da interação sombreamento x gramínea mostra que, com exceção de $\boldsymbol{M}$. minutiflora, o florescimento de todas as espécies foi estatisticamente afetado pela luminosidade; em $\boldsymbol{A}$. gayanus, $\boldsymbol{P}$. maximum e $\boldsymbol{S}$. sphacelata houve resposta linear à crescente redução da intensidade luminosa, enquanto as duas espécies do gênero Brachiaria reagiram de forma quadrática (tabela 1).

Independente do nível de luminosidade, as plantas de $\boldsymbol{M}$. minutiflora não floresceram, fato já esperado, uma vez que essa espécie não possui florescimento contínuo e, na região em que o ensaio foi conduzido, sua floração ocorre, comprovadamente, no final do mês de maio, em época posterior à qual a característica em questão foi avaliada.

A redução moderada da intensidade luminosa (30\% de sombreamento) não alterou a densidade de inflorescências em A. gayanus. Com o sombreamento mais intenso (60\%), houve uma grande redução no florescimento dessa gramínea, entretanto, sob todos os níveis de luminosidade estudados essa espécie foi a que apresentou a maior densidade de inflorescências, significativamente superior às demais (tabela 1).

Sob luminosidade ambiente, as espécies do gênero Brachiaria não diferiram estatisticamente entre si quanto à densidade de inflorescências (tabela 1). Em B. Decumbens, o sombreamento inibiu totalmente a floração e somente as plantas cultivadas a pleno sol floresceram. Em B. Brizantha, a floração mais intensa também ocorreu sob luminosidade ambiente, havendo queda na densidade de inflorescências devido à redução da intensidade luminosa.

$\mathrm{O}$ sombreamento crescente resultou em inibição progressiva do florescimento em $\boldsymbol{P}$. maximum, resposta antagônica àquela observada em S. sphacelata, cujo florescimento acentuou-se à medida que a luminosidade diminuía.

A decrescente densidade de inflorescências observada com o sombreamento progressivo de $\boldsymbol{P}$. maximum cv. Vencedor é claramente divergente do comportamento relatado por WONG \& WILSON (1980) e OLIVEIRA \& HUMPHREYS (1986) em trabalhos com os cultivares Green e Gatton dessa espécie, onde houve florescimento prolífico independente do nível de luminosidade. O comportamento reprodutivo atípico de $\boldsymbol{S}$. sphacelata, em que houve maior produção de inflorescências sob luminosidade reduzida, também contrasta com aquele observado em outras espécies do mesmo gênero (KNAKE, 1972; VENGRIS \& DAMON Jr., 1976; BUBAR \& MORRISON, 1984).

A redução do crescimento reprodutivo em resposta à menor intensidade luminosa, como observado em A. gayanus, B. brizantha e $\boldsymbol{P}$. maximum, ou mesmo a sua completa inibição, conforme se constatou em B. decumbens, estão de acordo com os relatos de vários autores referentes a ensaios con- 
Tabela 1 - Densidade média de inflorescências (inflorescências $/ \mathrm{m}^{2}$ ) de gramíneas cultivadas sob três níveis de sombreamento (valores transformados para $\mathrm{x}+1)$.

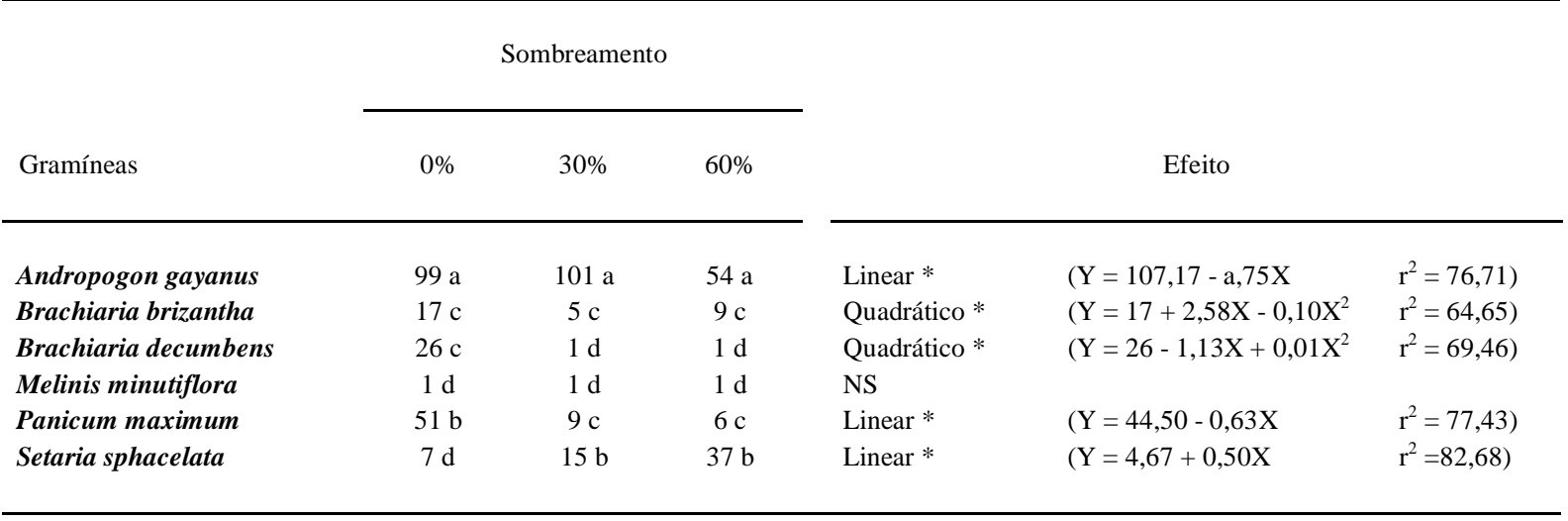

Em cada nível de sombreamento, médias seguidas de pelo menos uma mesma letra não diferem entre si pelo teste de Tukey a $5 \%$ de probabilidade.

* Significativo a 5\% de probabilidade pelo Teste F.

NS Não-significativo.

duzidos com diversas gramíneas (KNAKE, 1972; VENGRIS \& DAMON Jr., 1976; BUBAR \& MORRISON, 1984; DONG \& KROON, 1994) e leguminosas forrageiras (ZALESKI, 1964; ERIKSEN \& WHITNEY, 1982). Segundo KIGEL \& KOLLER (1970), o sombreamento reduz o número de inflorescências, além de retardar a sua emissão, devido à baixa intensidade de radiação ambiente limitar o suprimento de alguns metabólitos essenciais requeridos para o crescimento dessas estruturas reprodutivas.

Os resultados apresentados demonstram que a redução da intensidade luminosa no ambiente de cultivo afeta negativamente o florescimento das espécies A. gayanus, B. brizantha, B. decumbens e $\boldsymbol{P}$. maximum, estimulando-o em $\boldsymbol{S}$. sphacelata. A temática abordada ainda carece de mais estudos, envolvendo um período mais longo de avaliação que inclua a época de florescimento de $\boldsymbol{M}$. minutiflora na região, devendo estender-se até o período de maturação e colheita das sementes das gramíneas envolvidas, possibilitando a quantificação dessas e a análise de sua qualidade fisiológica.

\section{REFERÊNCIAS BIBLIOGRÁFICAS}

ARMITAGE, A.M., WETZSTEIN, H.Y. Influence of light intensity on flower initiation and diferentiation in hybrid geranium. HortScience, Alexandria, v. 19, n. 2, p. 114-116, 1984.

BUBAR, C.J., MORRISON, I.N. Growth response of green and yellow foxtail (Setaria viridis and S. lutescens) to shade. Weed Science, Champaign, v. 32, n. 6, p. 774-780, 1984.
DONG, M., KROON, H. Plasticity in morphology and biomass allocation in Cynodon dactylon, a grass species forming stolons and rhizomes. Oikos, Copenhagen, v. 70, n. 1, p. 99106, 1994.

ERIKSEN, F.I., WHITNEY, A.S. Growth and N fixation of some tropical forage legumes as influenced by solar radiation regimes. Agronomy Journal, Madison, v. 74, n. 5, p. 703$709,1982$.

KAMEL, M.S. A physiological study of shading and density effects on the growth and the efficiency of solar energy conversion in some field crops. Netherlands Journal of Agriculture Science, Wageningen, v. 59, n. 1, p. 5-16, 1959.

KESSLER, J.R., ARMITAGE, A.M. Effects of shading on growth rate, flower initiation and flower development of Begonia $\mathrm{x}$ Semperflorens-cultorum. Journal of Horticultural Science, Ashford Kent, v. 67, n. 6, p. 849-854, 1992.

KIGEL, J., KOLLER, D. Analysis of the control of development in Oryzopsis miliacea by the light environment. Journal of Experimental Botany, London, v. 21, n. 69, p. 1003-1016, 1970.

KNAKE, E.L. Effect of shade on giant foxtail. Weed Science, Champaign, v. 20, n. 6, p. 588-592, 1972.

OLIVEIRA, P.R.P., HUMPHREYS, L.R. Influence of level and timing of shading on seed production in Panicum maximum cv. Gatton. Australian Journal of Agricultural Research, East Melbourne, v. 37, n. 4, p. 417-424, 1986.

RYLE, G.J.A. Effects of light intensity on reproduction in S 48 timothy (Phleum pratense L.). Nature, London, v. 191, n. 4784, p. 196-197, 1961.

RYLE, G.J.A. Effects of shading on inflorescence size and development in temperate perennial grasses. Annals of Applied Biology, Warwickshire, v. 59, n. 2, p. 297-308, 1967. 
SNELGAR, W.P., MANSON, P.J., HOPKIRK, G. Effect of overhead shading on fruit size and yield potential of kiwifruit (Actinidia deliciosa). Journal of Horticultural Science, Ashford Kent, v. 66, n. 3, p. 261-273, 1991.

STRUIK, P.C. The effects of short and long shading, applied during different stages of growth, on the development, productivity and quality of forage maize (Zea mays L.). Netherlands Journal of Agricultural Science, Wageningen, v. 31 , n. 2 , p. 101-124, 1983.

VENGRIS, J., DAMON Jr., R.A. Field growth of fall panicum and witchgrass. Weed Science, Champaign, v. 24, n. 2, p. 205-208, 1976.

WONG, C.C., WILSON, J.R. Effects of shading on the growth and nitrogen content of green panic and siratro in pure and mixed swards defoliated at two frequencies. Australian Journal of Agricultural Research, East Melbourne, v. 31, n. 3 , p. $269-285,1980$

ZALESKI, A. Effect of density of plant population, photoperiod, temperature and light intensity on inflorescence formation in white clover. Journal of the British Grassland Society, Aberystwyth,, v. 19, n. 2, p. 237-247, 1964.

Ciência Rural, v. 30, n. 1, 2000. 